\title{
Os Gêneros Discursivos em Prática de Análise Linguistica: um estudo de planos de aula do portal do professor
}

\author{
Discourse Genres In The Practice Of Linguistic Analysis: A Study \\ Of Lesson Plans On The Teacher's Gate
}

\begin{abstract}
Cristiana Abrantes Sarmento ${ }^{1}$ José Cezinaldo Rocha Bessa²
\end{abstract}

\section{Resumo}

Assumindo os gêneros do discurso como objeto de ensino e de aprendizagem em aulas de língua portuguesa na educação básica e compreendendo que a análise linguística constitui uma prática de linguagem crucial no trabalho com gêneros discursivos, este artigo visa a analisar propostas de trabalho com gêneros em prática de análise linguística configuradas em planos de aula do Portal do professor. Do ponto de vista teórico, o artigo tem como respaldo estudos sobre os gêneros na perspectiva bakhtiniana, bem como trabalhos de Geraldi (2012), Mendonça (2006; 2007), Santos, Teixeira e Riche (2012), dentre outros estudiosos que abordam a prática de análise

\footnotetext{
${ }^{1}$ Graduada em Letras com habilitação em Língua Portuguesa e suas respectivas Literaturas. Mestra em Ensino de Línguas pelo Programa de Pós-Graduação em Ensino, da Universidade do Estado do Rio Grande do Norte/Campus de Pau dos Ferros. Atuou como bolsista no Programa Institucional de Bolsa de Iniciação à Docência- PIBID/UERN, no período de julho de 2012 a fevereiro de 2014. E-mail: cris_fechosa@hotmail.com.

${ }^{2}$ Possui graduação em Letras/Língua Portuguesa e respectivas literaturas pela Universidade do Estado do Rio Grande do Norte (2005), mestrado em Estudos da Linguagem, na área de concentração em Linguística Aplicada, pela Universidade Federal do Rio Grande do Norte (2007), e doutorado em Linguística e Língua Portuguesa pela Universidade Estadual Paulista Júlio de Mesquita Filho, Campus de Araraquara, com período de estágio de doutorado no exterior na Université de Paris VIII (bolsa PDSE/CAPES), supervisionado pela Profa Marília Amorim. Atualmente é Professor Adjunto IV da Universidade do Estado do Rio Grande do Norte, no Campus de Pau dos Ferros, onde atua nos cursos de graduação em Letras. É docente permanente e coordenador do Programa de Pós-Graduação em Ensino (PPGE/UERN), Mestrado Acadêmico, e docente permanente do Programa de Pós-Graduação em Letras da UERN (PPGL), Mestrado Acadêmico e doutorado. Foi o idealizador e é o atual editor-geral da revista Diálogo das Letras. É membro do Conselho editorial das Edições UERN. Concentra interesse pelos estudos na área de Letras, com ênfase em Linguística, Linguística Aplicada e Língua Portuguesa, dedicando-se especialmente a estudos informados pelas seguintes temáticas: gêneros do discurso, produção textual, ensino de língua materna, dialogismo, discurso citado, voz autoral, plágio, escrita e comunicação científica
}

Interfaces da Educ., Paranaíba, v.10, n.30, p. 79 - 99, 2019

ISSN 2177-7691

Recebido em Julho de 2019 e aprovado em Novembro de 2019 
linguística no contexto do ensino de língua portuguesa. Trata-se de uma pesquisa de natureza interpretativa e de abordagem qualitativa. O corpus de análise constitui-se de 04 planos de aula de língua portuguesa selecionados do Portal do professor cuja proposta de trabalho visa a abordagem da análise linguística no ensino fundamental. A análise realizada aponta que os planos apresentam propostas de ensino de análise linguística pouco producentes e, por vezes, pouco capazes de viabilizar a formação de alunos-leitores conscientes da função de escolhas linguísticas no funcionamento enunciativo-discursivo da linguagem.

Palavras-chave: Gêneros do discurso. Prática de análise linguística. Língua portuguesa. Planos de aula.

\section{Abstract}

Considering the discourse genres as an object of teaching and learning in Portuguese language classes in basic education and understanding that linguistic analysis constitutes a crucial language practice in working with discursive genres, this article aims at analyzing genre-based proposals in practice of linguistic analysis structured in lesson plans of the teacher's gate (Portal do Professor). From the theoretical point of view, the research is supported by studies on genres under a Bakhtinian perspective, as well as works by Geraldi (2012), Mendonça (2006; 2007), Santos, Teixeira and Riche (2012), among other scholars, who deals with the practice of linguistic analysis in the context of teaching of Portuguese Language. It is a research of an interpretative nature and a qualitative approach. The corpus of analysis consists of 04 Portuguese lesson plans from the Teacher's gate whose work proposal aims at approaching the linguistic analysis at elementary teaching level. The analysis which were carried out indicate that the plans present teaching proposals of linguistic analysis that are not very productive and, at times, are not capable of enabling the formation of readers students aware of the function of linguistic choices in the enunciative and discursive functioning of language. 
Keywords: Discourse genres. Practice of linguistic analysis. Portuguese language. Lesson plans.

\section{Introdução}

Todo ato de interação comunicativa se dá sempre na forma de um determinado gênero discursivo, que está sempre vinculado a uma ação humana (FARACO, 2009). Assim, toda atuação discursiva dos sujeitos que falam/escrevem se dá a partir de um gênero discursivo, que condiciona as formas de ser e de dizer do sujeito em sociedade.

Nessa linha de compreensão, é fato indiscutível que os gêneros discursivos traduzem as diferentes práticas sociais de interação de que os sujeitos participam e, por consequência, a funcionalidade da linguagem enquanto prática de (inter)ação humana, conforme sustenta o pensamento bakhtiniano. Coadunando-se, em boa medida, com essa compreensão, documentos oficiais do ensino, Parâmetros Curriculares Nacionais (BRASIL, 1998), Base Nacional Comum Curricular (BRASIL, 2017) e pesquisadores da linguagem, tais como Acosta (2013), Mendonça (2006; 2007), Maieski (2005) e Silva (2014) defendem que os gêneros ${ }^{3}$ sejam o ponto de partida para o ensino e para a aprendizagem de língua portuguesa na educação básica, tanto no momento do trabalho com a leitura e a produção de textos quanto no momento de desenvolvimento da prática de análise linguística.

Em consonância com esse entendimento expresso acima, assumimos aqui que a análise linguística se constitui uma prática de linguagem "crucial no trabalho pedagógico com os gêneros" (MENDONÇA, 2007). Sua relevância se dá enquanto prática de linguagem capaz de contribuir para que o aluno compreenda enunciados materializados em diferentes gêneros - como se pode constatar em trabalhos como os de Mendonça (2006, 2007), Santos, Teixeira e Riche (2012) e Segato (2016). O que significa dizer que tal prática serve não apenas para que se nomeie, classifique e/ou identifique elementos da língua, mas, principalmente, para compreender o querer dizer do sujeito

\footnotetext{
${ }^{3}$ Queremos destacar que, a despeito de nos reportar tanto a estudiosos que utilizam a noção de gênero textual quanto àqueles que se filiam à noção de gênero do discurso (Ver ROJO, 2005; CASSETARI, 2012, BEZERRA, 2017 , dentre outros, sobre a discussão em torno da distinção entre gênero textual e gênero do discurso), optamos aqui por assumir o termo gêneros do discurso, dada a nossa ancoragem central na perspectiva bakhtiniana.
}

Interfaces da Educ., Paranaíba, v.10, n.30, p. 79 - 99, 2019 
quando usa "esta" e não "aquela" palavra, a qual pode carregar múltiplos sentidos (ANTUNES, 2003; GERALDI, 1997, 2017).

Decorre daí que a análise linguística, quando trabalhada pelo professor levando em conta não apenas a palavra de forma isolada, mas as situações reais de enunciação em que os usuários da lingua se encontram inseridos, pode, conforme Acosta (2013), contribuir significativamente para alargar a compreensão dos alunos acerca do que os sujeitos enunciam ao fazerem uso da linguagem e, por assim dizer, dos diferentes gêneros que refletem e refratam a diversidade de realidades e ações humanas.

Nesse contexto, levando em conta que o livro didático, mesmo sendo um recurso didático central, mas não o único, ao qual o professor de língua portuguesa recorre para amparar a sua prática em sala de aula, e sabendo da facilidade com que se propaga o que é veiculado na internet, e admitindo ainda a recorrência, por parte de professores do Ensino Fundamental II, a esse meio de acesso a informações, elegemos como objeto de estudo, neste trabalho, planos de aula de análise linguística que circulam na internet. Nosso objetivo, portanto, é analisar propostas de trabalho com os gêneros discursivos em prática de análise linguística configuradas em planos de aula do Portal do professor.

Para a realização desse trabalho de investigação, tomamos como fundamento teórico os estudos de Bakhtin (2011) e pesquisadores como Faraco (2009) e Rojo (2002) que discutem sobre os gêneros em perspectiva bakhtiniana. Buscamos respaldo ainda em estudos de Geraldi (2012), Mendonça (2006; 2007), Santos; Teixeira e Riche (2012), que abordam a prática de análise linguística no contexto do ensino de língua portuguesa.

Além da presente introdução, o artigo apresenta uma seção de discussão teórica, na qual realizamos algumas considerações acerca do trabalho com os gêneros em práticas de análise linguística no ensino de língua portuguesa. Em seguida, temos a seção metodológica, em que sintetizamos as principais direções metodológicas assumidas no trabalho. Posteriormente, consta a seção de análise das propostas de trabalho com os gêneros em prática de análise linguística configuradas nos planos de aula do Portal do professor, e, por fim, trazemos às conclusões. 


\section{Gêneros discursivos, análise linguística e ensino de lingua portuguesa}

O intercâmbio verbal se realiza de diferentes maneiras, dependendo do que se quer dizer e do lugar que os sujeitos ocupam em dado contexto enunciativo. Assim, nas trocas comunicativas, os enunciados dizem sobre os sujeitos e sobre a forma como eles vivem e se comunicam em sociedade. Esse modo de pensar o funcionamento do intercâmbio verbal se firma na compreensão de que a língua se insere na vida do sujeito por meio de enunciados concretos (BAKHTIN, 2011).

$\mathrm{Na}$ visão do pensador russo, as diferentes maneiras de manifestação discursiva estabelecem vínculo estreito com a própria vida dos sujeitos, pois refletem as ações deles em suas diferentes esferas de atividade. Por meio da linguagem, o sujeito confirma, nega, interroga, responde, agride, transmite paz, o que tem a ver com o fato de que, "na realidade, não são palavras o que pronunciamos ou escutamos, mas verdades, mentiras, coisas boas ou más" (BAKHTIN/VOLOCHINOV, 2009, p. 99). Logo, nessa perspectiva, as palavras estão sempre carregadas de valores e sentidos que dizem sobre o sujeito e sobre aquilo que ele pensa, fala, escreve, etc.

Por conseguinte, "falar não é, portanto, apenas atualizar um código gramatical num vazio, mas moldar o nosso dizer às formas de um gênero, no interior de uma atividade" (FARACO, 2009, p. 127). Falar, assim como escrever, isto é, manifestar um projeto de dizer, não consiste em proferir palavras desvinculadas de um contexto, sem nenhum objetivo que seja. Falar e escrever são, portanto, enunciações carregadas de valores, de posicionamentos sociais; são, em última instância, formas de agir socialmente. Nesse sentido, nossos dizeres são sempre ajustados em função de um dado gênero, que, por corresponder a dada esfera comunicativa, assim como a dada atividade que reflete ações de sujeitos historicamente situados, não se dão de qualquer jeito, mas atendem a determinadas exigências, próprias da situação comunicativa em evidência.

Esse modo de compreender o funcionamento da linguagem tem implicações e consequências muito importantes para um ensino de língua portuguesa configurado nas diferentes práticas de linguagem, como tem sido Interfaces da Educ., Paranaíba, v.10, n.30, p. 79 - 99, 2019 
postulado em documentos oficiais do ensino e como discutido em diversos trabalhos da área em nosso país. No que concerne à prática de análise linguística, que nos interessa aqui, a assunção de uma concepção sócio discursiva do funcionamento da linguagem e uma perspectiva de trabalho com gêneros discursivos são direcionamentos fundamentais para aqueles que se comprometem com um ensino de lingua materna produtivo.

De acordo com Mendonça (2006), o que faz da análise linguística uma prática coerente e eficaz no ensino e na aprendizagem de língua portuguesa é justamente o ato de refletir sobre os efeitos de sentidos implicados nas diversas formas de fazer uso da linguagem, uso esse que se concretiza por meio da recorrência aos diferentes gêneros, os quais podem influenciar na formação de leitores-escritores de diferentes textos e, portanto, capacitá-los a participarem com autonomia e segurança das diversas situações sociais que implicam sempre o uso da linguagem.

"Quer dizer, ter o texto como unidade e os gêneros do discurso como objeto de ensino-aprendizagem pode possibilitar ao aluno o domínio das variadas práticas de linguagem, ou seja, das práticas discursivas" (MAIESKI, 2005 , p. 44). Isso porque considerar os gêneros discursivos em sala de aula como objeto de ensino e de aprendizagem é dar margem para se pensar a língua no seu sentido real, concreto, histórico, na sua função enquanto meio de interação humana.

Nesse sentido, os gêneros do discurso devem ser concebidos como o ponto de partida para qualquer atividade em sala de aula, a considerar que "a vontade discursiva do falante se realiza antes de tudo na escolha de um certo gênero do discurso" (BAKHTIN, 2011, p. 282), afinal, é deles que o aluno faz uso nas diferentes situações de interação que se dão dentro e fora da escola. Por isso, as atividades de ensino de lingua materna não devem fugir do trabalho com os gêneros do discurso, pois, como bem ressalta Rojo (2002, p. 39),

[...] tomar os gêneros do discurso como objeto de ensino é permitir ao aluno constituir-se como sujeito que faz uso da linguagem, inserindo-o em atividades que envolvem tanto capacidades linguísticas ou linguístico-discursivas, como capacidades 
propriamente discursivas, relacionadas à apreciação valorativa da situação comunicativa e capacidades de ação em contexto.

Em conformidade com o exposto, dar aos gêneros do discurso lugar de destaque em sala de aula (embora não exclusivo), isto é, compreendê-los como objeto no ensino de língua portuguesa é oferecer ao aluno a possibilidade de agir conscientemente como sujeito social, capaz de intervir e modificar o mundo em que vive, tendo em vista que o trabalho com os gêneros possibilita não apenas a compreensão de elementos linguísticos da língua, mas, principalmente, dos elementos discursivos, os quais revelam atitudes, desmascaram realidades até então não percebidas, permitindo, portanto, compreender a produção dos sentidos para além do que está dito na superficie textual.

A "análise linguística, nessa perspectiva, envolve aspectos verbais e extra verbais dos gêneros do discurso, da textualidade (coesão e coerência, progressão temática etc.), da língua e das convenções da escrita (problemas de ordem fonológica, morfológica e sintática, pontuação, etc.)" (MAIESKI, 2005, p. 59), o que sinaliza que ela não se limita à estrutura gramatical do texto, mas comporta o texto na sua totalidade, na sua função enquanto atividade enunciativa que existe para possibilitar a comunicação entre os sujeitos. Por isso, a análise linguística serve como apoio na construção e reconstrução de textos, assim como para que se compreenda como os sujeitos, nas suas diferentes maneiras de se comunicar, fazem uso da linguagem, isto é, como selecionam e por que selecionam determinadas palavras para estabelecer relações dialógicas com o outro.

Decorre daí que a efetivação da prática de análise linguística implica um olhar diferenciado para a função dos diversos recursos linguísticos nos diferentes gêneros, posto que, como enfatiza Mendonça (2007, p. 8),

[...] a variabilidade de funções dos recursos linguísticos nos diversos gêneros só se torna um principio claro para os aprendizes se também há um trabalho diferenciado, específico com cada gênero a ser explorado na escola, em que se promovam reflexão sobre como se constituem. 
Nessas circunstâncias, para que a análise linguística cumpra sua função como prática de linguagem em sala de aula e, por conseguinte, como apoio na compreensão dos diferentes gêneros a que o aluno - na condição de aprendiz e de sujeito dialógico - deve ter acesso, se faz necessário um trabalho diferenciado com cada gênero para que os aprendizes não apenas reconheçam o uso de dados recursos linguísticos, mas, sobretudo, compreendam os interesses específicos que, por vezes, se camuflam por meio de determinadas escolhas, as quais influenciam na constituição de cada enunciado.

Assim, concordamos com Mendonça (2006; 2007), Santos; Riche e Teixeira (2012) e Acosta (2013), quando defendem que o sentido da prática de análise linguística reside na exploração dos elementos que dão conta das ações situadas dos sujeitos em determinados contextos enunciativos. Provém daí que ensinar os textos de forma geral, bem como os recursos expressivos que neles se manifestam, sem levar em conta as condições reais em que se dá a produção de dado gênero, pode resultar em atividades de análise linguística pouco ou nada produtivas para o ensino e para a aprendizagem da língua portuguesa.

Mendonça (2007) nos parece enfática quando ressalta que ensinar, por exemplo, sobre adjetivos, tempos verbais e/ou outros recursos expressivos de forma generalizada não viabiliza a compreensão de dadas escolhas. Por isso, propõe-se o entendimento de tais recursos de maneira situada, contextual, considerando as possibilidades expressivas das palavras na construção de sentidos de determinado gênero, tendo em vista que cada um tem uma maneira peculiar de se constituir e funcionar socialmente. Isso nos permite compreender que cada recurso pode desempenhar uma função distinta, a depender do gênero e do querer dizer do sujeito-autor (GOLDSTEIN, 2009).

Com isso, compreendemos, pois, que o professor, em suas atividades de análise linguística não deve estabelecer como prioridade apenas o ensino de conceitos gramaticais que falam sobre a lingua, a não ser em caso em que o ensino de dado conceito seja necessário para que se compreenda alguma situação de comunicação. Logo, como aponta Geraldi (2012, p. 46), as Interfaces da Educ., Paranaíba, v.10, n.30, p. 79 - 99, 2019 
atividades devem se deter ao "ensino da língua e apenas subsidiariamente se deverá apelar para a metalinguagem, quando a descrição da língua se impõe como meio para alcançar o objetivo final do domínio da língua, em sua variedade padrão". Dessa forma, a atividade de descrição da língua é importante, desde que acompanhada de alguma finalidade no que compete à preparação do aluno para dadas atividades comunicativas, uma vez que "as classificações metalinguísticas não são protagonistas, mas coadjuvantes do processo" (GOLDSTEIN, 2009, p. 96).

Nessa perspectiva, "em lugar da classificação e da identificação, ganha espaço a reflexão" (MENDONÇA, 2006, p. 208), reflexão essa que se detêm as diferentes situações enunciativas de que os alunos participam como sujeitos que desempenham diferentes papéis em sociedade. Assim, são esses diferentes papéis que devem servir como motivação para o ensino e para a aprendizagem de lingua portuguesa e, por assim dizer, para o trabalho com textos em prática de análise linguística, o qual deve acontecer mediante os gêneros discursivos que são por eles utilizados nos diferentes diálogos que estabelecem e/ou precisam estabelecer com outros sujeitos. Desse modo, o que caracteriza a análise linguística enquanto prática de linguagem é, de fato, a sua pertinência em contribuir para o entendimento das escolhas feitas pelos sujeitos atuantes em sociedade, ao assumirem a palavra no interior de uma dada esfera de atividade humana.

\section{Metodologia}

A atividade de investigação aqui relatada assume, em seu direcionamento teórico-metodológico, que não existe palavra/ação neutra dos sujeitos em suas práticas sociais, inclusive no trabalho desenvolvido pelo pesquisador, nos diferentes momentos da realização de sua investigação. Em consonância com esse posicionamento sobre linguagem e construção do saber assumido acima, nosso estudo se enquadra numa abordagem qualitativa de pesquisa, em diálogo com o pensamento de Oliveira (2007) e Laville e Dionne (1999).

O estudo se caracteriza ainda por sua natureza interpretativa (AMORIM, 2016), já que, lidando com linguagem e produção de sentidos, o Interfaces da Educ., Paranaíba, v.10, n.30, p. 79 - 99, 2019 
foco de atenção do pesquisador se concentra, seguindo o que afirma Bakhtin (2011), na intepretação dos sentidos produzidos pelos sujeitos, que é característica do fazer científico nas ciências humanas, afinal, "a especificidade das ciências humanas reside no fato de serem ciências do discurso" (AMORIM, 2016, p. 21).

Considerando os objetivos da pesquisa, o corpus de análise constituise de 04 planos de aula de língua portuguesa direcionados ao ensino fundamental, coletados no Portal do professor. Este portal, criado em 2007, é um site educacional do Ministério da Educação (MEC) destinado a professores de diversas disciplinas. O seu objetivo é socializar diferentes materiais didáticos e possibilitar a interação com educadores de todo o Brasil.

O site se constitui por algumas seções, a saber, Multimídia, Recursos educacionais, Materiais de estudo, Notícias, Colaboração, Links. Dispõe, ainda, da opção Visite também e do Espaço da aula. Na imagem reproduzida abaixo, recortada em 20 de abril de 2018, podemos visualizar a página inicial do referido portal:

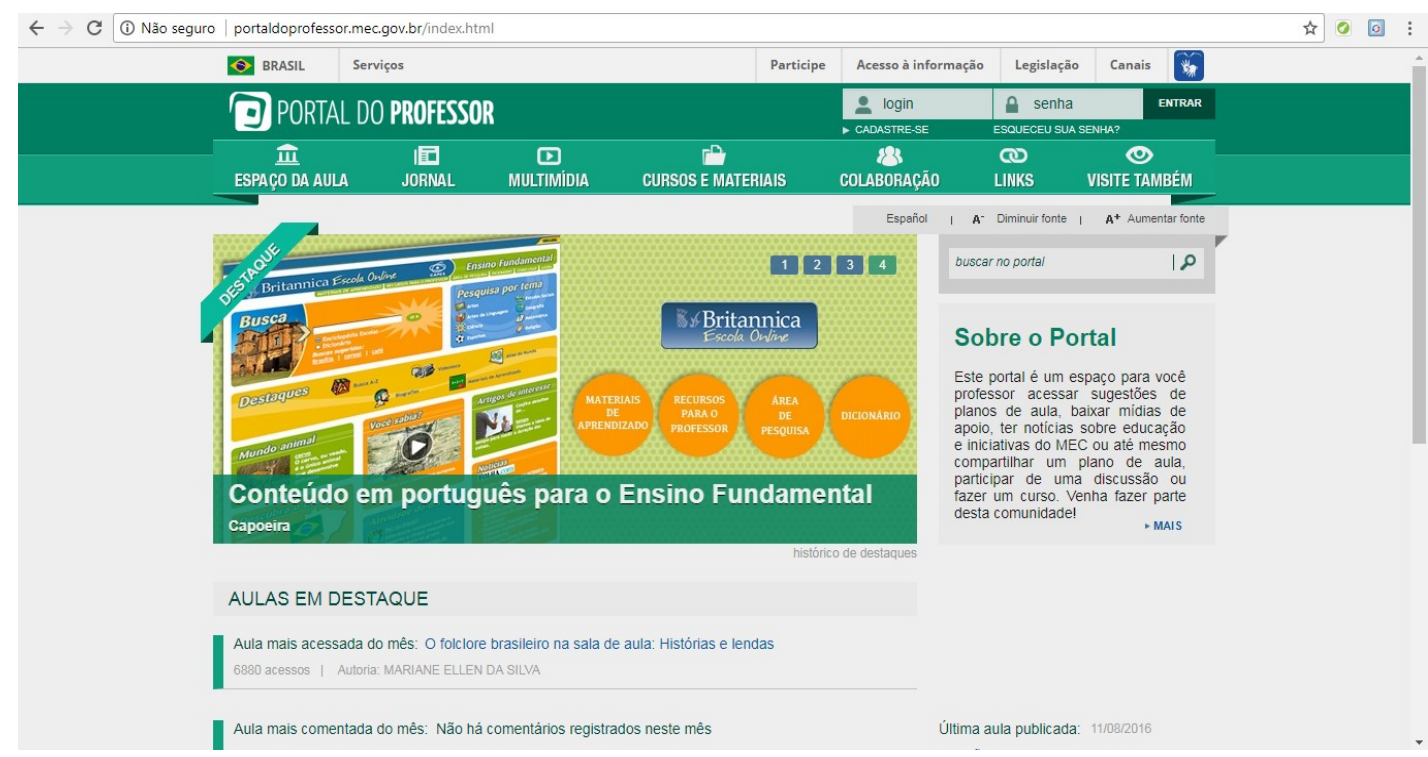

Fonte: Página inicial do Portal do Professort

\footnotetext{
${ }^{4}$ Disponível em: http://portaldoprofessor.mec.gov.br/index.html. Acesso em: 15 de novembro de 2017. Interfaces da Educ., Paranaíba, v.10, n.30, p. 79 - 99, 2019
} 
Nessas seções, é possivel visualizar/baixar recursos multimídia (como vídeos, mapas, textos e imagens), que podem ser localizados na opção Recursos Educacionais. Podemos também ter acesso a documentos oficiais voltados para a educação, os quais podem ser acessados na opção Materiais de estudo. Além disso, podemos tomar conhecimento acerca do que acontece em contextos escolares a partir de informações disponíveis na opção Notícias. Encontramos também um jornal que discute sobre assuntos diversos que podem estar relacionados com escolas em geral e/ou com professores e/ou alunos de todo o país. Temos, ademais, a opção Colaboração, que oferece cursos de capacitação, tais como: de introdução à educação digital, entre outros. Na opção Links, é possivel ter acesso a blogs contendo relatos de experiências vivenciadas por professores. Já na parte Visite Também pode-se ter acesso a espaços como TV Escola, que fornece conteúdos relacionados a jogos, etc.

Os planos de aula, nosso foco de interesse, podem ser localizados na opção Espaço da Aula. Nele, o professor tem a oportunidade de visualizar e conhecer sugestões de atividades diversas (as quais podem ser acessadas por assunto, por nivel de ensino e etc.), voltadas para diferentes disciplinas, assim como para diferentes turmas de alunos do Ensino Fundamental e Médio. Há, ainda, a possibilidade de compartilhar/baixar esses materiais, de opinar sobre eles e de criar novos planos de aula. Para isso, se faz necessário que o professor se cadastre, faça um login na página do portal e siga o passo a passo que o site disponibiliza para quem deseja propor alguma atividade e queira socializar com outros educadores.

Assim, por meio desse site, é possivel acessar, compartilhar e criar materiais didáticos diversificados. Com isso, o Portal do Professor se constitui um espaço que está ligado à segunda geração da Web, isto é, a Web 2.0, já que os internautas e professores, ao terem acesso ao site, podem não somente acessar as informações que nele constam como também construir novas informações, tornando-se, no dizer de Leffa (2003), participantes ativos do processo de construção do conhecimento, contribuindo, por exemplo, com a criação de novos materiais didáticos. 


\title{
O trabalho com gêneros discursivos na prática de análise em planos de aula do Portal do Professor
}

Nesta seção, concentramo-nos na análise das propostas de trabalho com os gêneros discursivos em prática de análise linguística configuradas em planos de aula de lingua portuguesa do Portal do professor. Para os propósitos da análise aqui realizada, elegemos 04 planos direcionados ao ensino fundamental que apresentam propostas de trabalho com os gêneros discursivos crônica humorística, notícia, artigo de opinião e carta do leitor, das quais trazemos alguns recortes para nosso exame.

Iniciamos com a análise da crônica humorística. Focalizamos uma questão recortada do plano P1A25, que tem como objetivo explorar a pessoa gramatical, a partir da crônica humorística de Fernando Veríssimo, intitulada "O flagelo do vestibular".

\begin{abstract}
P1A2
A crônica "O flagelo do vestibular" é escrita em primeira pessoa. Transcreva do segundo parágrafo do texto uma expressão que comprove que o narrador é o próprio autor, isto é, o autor fala de si mesmo.
\end{abstract}

Em P1A2, a atividade proposta se desenvolve a partir da afirmativa de que a crônica "O flagelo do vestibular" é escrita em $1^{\text {a }}$ pessoa. Ela leva em conta esse apontamento, para, em seguida, solicitar que o aluno "transcreva do segundo parágrafo do texto uma expressão que comprove que o narrador é o próprio autor, isto é, fala de si mesmo".

De acordo com o que é exigido na questão, reconhecer e compreender a pessoa gramatical de um enunciado parece se resumir à ação de apontar no texto e/ou copiar de um parágrafo do texto "uma expressão". Em outras palavras, o P1A2, ao abordar a pessoa gramatical no gênero crônica, dá ênfase ao ato de transcrição desse elemento em detrimento da forma como esse elemento é escolhido para compor o enunciado e de como pode ser entendido pelo leitor, para quem o texto é direcionado.

\footnotetext{
${ }^{5}$ Os planos analisados foram identificados por P1, $\mathrm{P} 2$ e etc., em que $\mathrm{P}=\mathrm{Plano}$, e 1 e 2 designam número de ordem de cada plano. Além disso, usaremos A1, A2 e etc., em que A = Atividade, e 1 e 2 correspondem a número de ordem das atividades. Desse modo, P1, A1 corresponde a plano 1 e atividade 1.
}

Interfaces da Educ., Paranaíba, v.10, n.30, p. 79 - 99, 2019 
Convém ressaltar que, no gênero crônica, a pessoa gramatical não é mobilizada de uma única forma, podendo, pois, oscilar da $1^{\mathrm{a}}$ (eu, nós) para a $3^{\mathrm{a}}$ (ele, eles), e, em alguns casos, para a $2^{\mathrm{a}}$ (tu) (GOLDSTEIN, 2009), a depender das intenções comunicativas do sujeito produtor/autor. O que significa dizer que gêneros, sobretudo os de caráter opinativo - como é o caso da crônica - permitem que o autor se posicione a partir de suas experiências, inclua seus possiveis leitores no seu projeto discursivo e, ainda, se afaste daqueles que não influenciam de forma positiva na construção do seu enunciado, conforme seja a sua intenção comunicativa e o seu objetivo de convencer os leitores previstos acerca de suas ideias.

Assim, concordamos com Goldstein (2009) quando, ao propor formas de se trabalhar a pessoa gramatical no gênero crônica, afirma que a seleção da pessoa verbal pode estar atrelada ao estilo do cronista ou se tratar de uma estratégia para alargar o entendimento do texto. Nesse sentido, destacamos que importa pouco para a aprendizagem do aluno acerca do funcionamento da linguagem saber se o enunciado é escrito em $1^{\text {a }}$ pessoa do singular ou do plural, se não se levar em conta os sentidos que dadas escolhas imprimem ao enunciado, logo é muito mais relevante e produtivo saber como o autor faz uso desses elementos para tornar compreensivel e dialógico o seu projeto de dizer.

O P2A2 trabalha com o gênero carta do leitor, mais especificamente com uma carta de autoria de Maria das Graças Monteiro. Esta carta é construída em resposta a uma reportagem sobre ansiedade, publicada na revista "Superinteressante". Da proposta de trabalho com esse gênero explorando a análise linguística, destacamos uma das perguntas que elegem o adjetivo como objeto de estudo.

P2A2

O autor da carta 1 começa apontando qualidades da matéria "Sobre ansiedade". Quais são essas qualidades? Qual classe gramatical dessas palauras?

A questão propõe que o aluno responda, considerando a leitura da carta do leitor, quais as qualidades que a autora aponta, no início do texto, 
sobre a matéria lida e qual a classe gramatical das palavras utilizadas. Nesse contexto, a proposta é que o adjetivo seja estudado pelo aluno como um elemento que tem a função de qualificar. No caso proposto em P2, o adjetivo está sendo usado para assinalar as qualidades do texto, materializado no gênero reportagem, que discorre sobre a ansiedade.

$\mathrm{O}$ adjetivo tem, como sabemos, a função de qualificar, entretanto, uma vez escolhido pelo produtor da carta para compor o seu enunciado, seu emprego não se limita tão somente e necessariamente a tal função. O seu uso vai além, contribuindo para ratificar o posicionamento, o querer dizer, as impressões/valorações daquele que escreve sobre um dado tema (BAKHTIN, 2011), inscrito em dado lugar social, que é, neste caso, o campo jornalístico de caráter opinativo, representado pelo gênero carta do leitor e, em um contexto mais amplo, mais especificamente pela revista Superinteressante.

Desse modo, o autor da carta, ao produzir seu enunciado em resposta à reportagem, expõe não somente o seu posicionamento axiológico (que reflete a visão de um sujeito que leu a matéria e se identificou com o tema abordado, por estar enfrentando o problema da ansiedade e, por isso, constrói uma visão positiva acerca da matéria), como também as intenções da revista Superinteressante, que objetiva, quase sempre, transmitir uma imagem positiva sobre seus escritos, tomando como apoio, nesse caso, os dizeres dos próprios leitores.

Assim sendo, o professor, ao considerar o estudo do adjetivo em sala de aula, deve levar em conta não apenas a sua função de qualificar, mas, principalmente, sua função de, em um contexto enunciativo determinado (a exemplo do seu uso na carta do leitor), influenciar na construção de posicionamentos valorativos, contribuindo, portanto, para possibilitar que os alunos entendam as intenções que estão por trás da escolha de dados elementos linguísticos e a fazer uso deles em determinadas situações enunciativas (SANTOS; RICHE;TEIXEIRA, 2012).

A questão que segue explora a pontuação no gênero notícia e pertence ao P3A3. Ela é construída com base em dois enunciados, ambos do gênero notícia. A primeira delas está disponível na página da Folha Uol, e fala sobre Interfaces da Educ., Paranaíba, v.10, n.30, p. 79 - 99, 2019 
um acidente ocorrido em São Paulo, o qual deixa cinco pessoas feridas; e a segunda, na página do portal G1 Globo, e anuncia a realização de um show de Bon Jovi, no Rio de Janeiro.

\section{P3A3}

Dentre os sinais de pontuação, o ponto final é bastante usado em textos de noticia, entretanto, a interrogação e a exclamação nunca aparecem. Por quê?

Podemos observar que a questão em análise busca explorar o ponto final e afirma que este é bastante recorrente em textos do gênero notícia, ressaltando que, em contrapartida, os sinais de interrogação e exclamação nunca são utilizados e questiona o porquê. O questionamento sobre o motivo da não recorrência quanto aos pontos de interrogação e de exclamação no gênero notícia poderia possibilitar uma melhor compreensão sobre o uso da pontuação e sua importância na organização das ideias do sujeito enunciador, assim como o entendimento do porquê de o ponto final ser mais utilizado no gênero explorado, uma vez que abriria espaço para que o aluno conhecesse de maneira mais aprofundada esse gênero.

No entanto, a falta de referência explicita, no P3, aos enunciados que servem como base para a resolução das questões da atividade descaracteriza, em parte, a atividade de análise linguística, que deve ocorrer sempre mediante o texto, pois, como bem assinala Mendonça (2006), a escolha e o uso de dados, informações e estratégias devem acontecer em concordância com os textos, ou seja, em conformidade com quem fala, com a finalidade comunicativa e a partir de um determinado gênero.

Nessa perspectiva, seja qual for a questão ou atividade envolvendo a análise linguística deve sempre ter o enunciado como parâmetro, como ponto de partida, já que ele está atrelado a uma situação real de enunciação, que envolve sujeitos, que tem em mente objetivos a serem alcançados por meio da comunicação. Por esse viés, a análise linguística enquanto prática de linguagem não tem sentido fora da comunicação e nem pode ser ensinada de forma generalizada, mas levando em conta cada enunciado em sua singularidade e concretude. 
Desse modo, compreendemos, pois, que a questão explorada poderia ser pertinente para que o aluno compreendesse como esse gênero se constitui, caso tivesse tomado os dois enunciados como objeto de análise, uma vez que a partir deles os alunos poderiam entender, por exemplo, que a não recorrência ao ponto de exclamação ou de interrogação pode se justificar pelo fato de o gênero notícia possuir uma linguagem que se pretende objetiva e livre de marcas de subjetividade na maneira de conduzir os fatos e os acontecimentos a serem noticiados. Assim, opta-se por reafirmar a ideia de que o ponto final é uma marca bastante utilizada em textos pertencentes a esse gênero, de caráter informativo, desconsiderando, portanto, que, a depender das possibilidades expressivas, o produtor pode, por exemplo, fazer uso de outros sinais de pontuação que melhor se ajustem ao seu projeto de dizer.

Ao trabalhar em sala de aula a questão proposta em P3A3, sem relacioná-la explicitamente com o texto, isto é, com a situação comunicativa em evidência, o professor estará tirando do aluno a possibilidade de compreender o porquê da recorrência ao ponto final em textos do gênero notícia, uma vez que é somente por meio da enunciação que é possivel perceber os efeitos de sentido de tal uso.

Sendo assim, ao considerar que o ponto final é mais usado em "gêneros de notícia", sem mencionar os textos e nem induzir para uma compreensão dessa recorrência ao ponto final, a questão em análise parece deixar de lado a oportunidade de explorar os textos com suas peculiaridades e a funcionalidade do ponto final na organização da atividade enunciativa.

A questão abaixo pertence ao plano de aula P3A2, que se propõe a trabalhar o gênero artigo de opinião. Embasada no texto "Ambição e ética" de Kanitz, a questão se propõe a abordar o operador argumentativo mas.

P3A2

os operadores mas, porém, no entanto, todavia assinalam uma oposição entre argumentos explícitos $e$ implícitos no texto.

Releia essa passagem do texto - quinto parágrafo - e explique a relação de sentido introduzida pelo operador mas

Interfaces da Educ., Paranaíba, v.10, n.30, p. 79 - 99, 2019 
"A maioria dos pais se preocupa bastante quando os filhos não mostram ambição, mas nem todos se preocupam quando os filhos quebram a ética. Se o filho colou na prova, não importa, desde que tenha passado de ano, objetivo maior".

Conforme se vê, a questão propõe trabalhar o operador mas (que pode ser substituído por: porém, no entanto, todavia). Para tanto, traz um fragmento do artigo de opinião de Kanitz, "Ambição e ética", e solicita que os alunos releiam e expliquem "a relação de sentido introduzida pelo operador mas" naquele trecho.

Nesse sentido, a questão pertencente ao P3, ao tomar o texto de Kanitz como objeto de estudo, situa o aluno em relação ao operador mas, dando pistas acerca de sua função na construção de textos argumentativos/opinativos, afirmando que este marca oposição entre os argumentos visíveis e subtendidos no texto. Depois disso, solicita, por meio de um trecho do texto, que o aluno "explique a relação de sentido" estabelecida pelo operador argumentativo mas naquele contexto.

Percebe-se, com isso, que a preocupação da questão recai sobre a função do operador argumentativo mas no texto-enunciado. Essa preocupação é realçada quando o P3 pede para que o aluno "explique" o uso do operador, oferecendo, assim, ao aluno a possiblidade de construir sentido a partir da "relação" entre as partes do enunciado, de modo a fornecer meios para que ele amplie sua compreensão acerca da linguagem.

Levando em conta o dizer de Marchesani (2008), os operadores argumentativos, como parte constituinte da lingua, são escolhidos pelos usuários com o objetivo de avivar e situar a força de persuasão do enunciado; os operadores argumentativos servem, portanto, para que o articulista construa relações dialógicas com o seu leitor. No caso da questão em análise, essa relação se dá por meio de ideias opostas, que se marcam no uso do operador argumentativo mas, o qual permite que o autor imprima um acento de valor, isto é, emita um posicionamento acerca do que está sendo discutido, o que é esperado em um artigo de opinião. 
Assim sendo, a questão pertencente ao P3 fornece meios para que o professor trabalhe o operador argumentativo mas na perspectiva da interação, possibilitando que o aluno possa levar em consideração o uso do operador na construção do texto e, consequentemente, na produção de sentido, bem como em relação aos efeitos causados pela escolha desse elemento discursivo. Com isso, abre-se a possibilidade de se estudar a respeito do uso que determinadas expressões da língua cumprem na compreensão dos gêneros discursivos, uma vez que não se limita à localização do elemento no texto, mas se vai além, reportando-se, pois, a sua função e ao seu uso na construção dos argumentos do articulista.

Levando em conta as questões aqui suscitadas, bem como a proposição de atividades envolvendo os gêneros: cônica humorística, carta do leitor, notícia e artigo de opinião a partir da prática de análise linguística, podemos dizer que há, nos planos de aula, uma ênfase maior em explorar os enunciados dissociados das situações concretas de enunciação de que eles fazem parte, o que pouco (ou nada) contribui para um trabalho com os gêneros voltado para as reais intenções dos sujeitos que, por meio deles, se comunicam/interagem o tempo todo.

Nesse sentido, a prática de análise linguística perde por se constituir como uma atividade que está muito mais ligada ao exercício de localização de dados nos enunciados do que à compreensão de como os sujeitos-autores movimentam dados elementos na construção de suas impressões valorativas (abordagem de maior pertinência para a formação de alunos capazes de intervir no mundo com criticidade e segurança), o que deveria se constituir como objetivo maior para se tomar os gêneros discursivos como objeto de análise em sala de aula.

\section{Conclusão}

Fundamentados nos estudos discursivos bakhtinianos e em trabalhos voltados para a prática de análise linguística a partir dos gêneros, buscamos analisar propostas de trabalho com os gêneros discursivos em prática de análise linguística configuradas em planos de aula do Portal do professor. 
A análise dos recortes dos 04 planos de aula selecionados como corpus deste estudo nos levou a perceber que, no que diz respeito ao trabalho com os gêneros (crônica humorística, carta do leitor, notícia e artigo de opinião), há uma valorização maior dos aspectos linguísticos em detrimento dos aspectos discursivos; estes últimos aparecem em apenas uma questão das propostas de análise linguística examinadas (expresso por meio do uso do operador mas, que foi explorado no artigo de opinião).

Constatamos que, nos planos analisados, em lugar da exploração de tais aspectos em função de sua mobilidade nos enunciados - conforme o uso na construção da vontade enunciativa dos sujeitos-autores - ganha um espaço significativo a classificação e transcrição desses elementos, o que pode, por decorrência, levar os alunos a não realizarem reflexões sobre os enunciados, tampouco compreenderem que, por meio dos gêneros, produzimos significações e expressamos a realidade. Nesse sentido, entendemos que os planos ainda sinalizam para uma prática de ensino de análise linguística pouco producente e, por vezes, pouco capaz de viabilizar a formação de alunos-leitores críticos e conscientes da função de dadas escolhas no funcionamento enunciativo-discursivo da linguagem.

Levando em conta os resultados alcançados por meio dessa atividade de investigação, compreendemos, pois, que é de suma importância que o professor de língua portuguesa disponha de conhecimentos teóricos consistentes que possam ajudá-lo a construir suas aulas, de tal forma que lhe capacite cada vez mais para avaliar com criticidade informações que circulam na internet - tais como os planos de aula disponiveis em portais - e a se constituir como autor. Pensamos, portanto, em um professor-autor, que não sendo o primeiro e nem o último a propagar dados conhecimentos, aprende todos os dias a atualizar sua prática, assim como a construir e reconstruir conhecimentos, de forma consciente, de maneira que possa se tornar cada dia mais autônomo, conforme defende Demo (2009; 2015). E, nesse sentido, pensamos em um professor que possa contribuir para a formação de alunos capazes de fazerem uso da palavra, na escola ou fora dela, com proficiência e autonomia. 
Encerramos destacando que nossa pesquisa pode contribuir para que o professor de língua portuguesa desenvolva uma postura ainda mais crítica frente ao uso de materiais didáticos, que circulam na internet, no contexto de sala de aula (sobretudo, nesse atual cenário em que nos encontramos, no qual se fala sobre tudo e qualquer coisa de forma instantânea), com vistas à construção de conhecimentos por parte deste, assim como para a aprendizagem do aluno quanto aos gêneros discursivos enquanto expressão das diferentes ações e maneiras de fazer uso da palavra em sociedade.

\section{Referências}

ACOSTA, P. R. A prática de análise linguística mediada pelos gêneros do discurso: matizes sócio-históricos. Letrônica, Porto Alegre, v. 6, n. 2, p. 494-520, jul./dez., 2013.

AMORIM, M. As ciências humanas e sua especificidade discursiva. In: RODRIGUES, R.; PEREIRA, R. H. (Org.). Estudos dialógicos da linguagem e pesquisas em linguística aplicada. São Carlos: Pedro \& João editores, 2016. p. 17-45.

ANTUNES, I. Aula de português: encontro e interação. São Paulo: Parábola Editorial, 2003.

BAKHTIN, M. Estética da criação verbal. Tradução do russo de Paulo Bezerra. 6. ed. São Paulo: Martins Fontes, 2011.

M. (VOLOCHINOV). Marxismo e filosofia da linguagem: problemas fundamentais do método sociológico na ciência da linguagem. São Paulo: Hucitec 2009.

BEZERRA, B. G. Gêneros no contexto brasileiro: questões [meta] teóricas e conceituais. São Paulo: Parábola Editorial, 2017.

BRASIL. Secretaria de Educação Fundamental. Parâmetros curriculares nacionais: terceiro e quarto ciclos do ensino fundamental: lingua portuguesa. Brasília: MEC/SEF, 1998.

. Ministério da Educação. Base Nacional Comum Curricular. Brasília, 2017.

CASSETTARI, M. I. Tipo, gênero textual e gênero do discurso: em busca de uma definição para o ensino. Diálogo das Letras, Pau dos Ferros, v. 01, n. 02, p. $132-151$, jul./dez. 2012.

DEMO, P. O educador e a prática da pesquisa. Ribeirão Preto: Editora Alphabeto, 2009. P. Aprender como autor. São Paulo: Atlas, 2015.

FARACO, C. A. Linguagem \& diálogo: as ideias Linguísticas do círculo de Bakhtin. Curitiba: Parábola Editorial, 2009.

GERALDI, J. W. Portos de passagem. 2 ed. São Paulo: Martins Fontes, 1997. J. W. O texto na sala de aula. São Paulo: Anglo, 2012.

Interfaces da Educ., Paranaíba, v.10, n.30, p. 79 - 99, 2019 
GOLDSTEIN, N. Gêneros do discurso e gramática no ensino de língua materna. SCRIPTA, Belo Horizonte, v.13, n.24, p. 95-109, 2009.

LAVILLE, C.; DIONNE, J. A construção do saber. manual de metodologia da pesquisa em ciências humanas. Tradução de Heloisa Monteiro e Francisco Settineri. Portalegre: Artes Médicas, Sul Ltda; Belo Horizonte: Editora UFMG, 1999.

LEFFA, V. J. O ensino do inglês no futuro: da dicotomia para a convergência. In: STEVENS, C. M. T.; CUNHA, M. J. C. (Org.). Caminhos e colheita: ensino e pesquisa na área de inglês no Brasil. Brasília, 2003, v. 1. p. 225-250.

MAIESKI, M. N. O gênero do discurso artigo como objeto de ensino-aprendizagem: uma proposta de integração da prática de produção textual à leitura e à análise linguística. 2005. 285 f. Dissertação (Mestrado em Linguística) - Programa de Pós-Graduação em Linguística, Universidade de Santa Catarina, Santa Catarina, 2005.

MARCHESANI, S. A argumentação em editoriais e artigos de opinião: um estudo comparativo. 2008. 173 f. Dissertação (Mestrado em Letras). Programa de PósGraduação em Letras, Belo Horizonte, 2008.

MENDONÇA, M. Análise linguística no ensino médio: um novo olhar, um outro objeto. In: BUNZEN, C; MENDONÇA, M. (Org.). Português no ensino médio e formação do professor. São Paulo: Parábola, 2006. p. 199-226.

Análise linguística: refletindo sobre o que há de especial nos gêneros. In: SANTOS, C. F; MENDONÇA, M; CAVALCANTE, M. C. B (Org.). Diversidade textual: os gêneros na sala de aula. Belo Horizonte: Autêntica, 2007. p. 73-88.

OLIVEIRA, M. M. Como fazer pesquisa qualitativa. Petrópolis: Vozes, 2007.

ROJO, R. Gêneros do discurso e gêneros textuais: questões teóricas e aplicadas. In: MEURER, J. L.; BONINI, A.; MOTTA-ROTH, D. (Org.). Gêneros: teorias, métodos, debates. São Paulo: Parábola, 2005. p.184-207.

ROJO, R. Concepção de leitor e produtor de textos nos PCNs: Ler é melhor do que estudar. In: ROJO, R. (Org.). Leitura e Escrita na Formação de Professores. São Paulo: Editora Musa, 2002. p. 31-52.

SANTOS, L. W, RICHE, R.C, TEIXEIRA, C. S. Análise e produção de textos. São Paulo: Contexto, 2012.

SEGATO, M. C. Notícia e editorial: procedimentos de análise linguística e sua relação com a

construção de sentido nos gêneros jornalísticos. Diálogo das Letras, Pau dos Ferros, v. $05, \mathrm{n}$.

01, p. 217-233, jan./jun. 2016.

SILVA, S. L. Algumas considerações sobre memorial de leitura e a constituição do ethos discursivo na formação inicial do professor de língua portuguesa. Diálogo das Letras, Pau dos Ferros, v. 03, n. 02, p. 05-22, jul./dez. 2014.

SUASSUNA, L.; BERNARDINO, R. A. S. Passando em revista ideias sobre o ensino de lingua portuguesa: uma entrevista com João Wanderley Geraldi. Diálogo das Letras, Pau dos Ferros, v. 06, n. 01, p. 490-496, jan./jun. 2017. 